\title{
Mechanical Properties of Austenitic Stainless Steel Made by Additive Manufacturing
}

\author{
William E. Luecke and John A. Slotwinski \\ National Institute of Standards and Technology, \\ Gaithersburg, MD 20899 \\ william.luecke@nist.gov \\ John.Slotwinski@jhuapl.edu
}

\begin{abstract}
Using uniaxial tensile and hardness testing, we evaluated the variability and anisotropy of the mechanical properties of an austenitic stainless steel, UNS S17400, manufactured by an additive process, selective laser melting. Like wrought materials, the mechanical properties depend on the orientation introduced by the processing. The recommended stress-relief heat treatment increases the tensile strength, reduces the yield strength, and decreases the extent of the discontinuous yielding. The mechanical properties, assessed by hardness, are very uniform across the build plate, but the stress-relief heat treatment introduced a small non-uniformity that had no correlation to position on the build plate. Analysis of the mechanical property behavior resulted in four conclusions. (1) The withinbuild and build-to-build tensile properties of the UNS S17400 stainless steel are less repeatable than mature engineering structural alloys, but similar to other structural alloys made by additive manufacturing. (2) The anisotropy of the mechanical properties of the UNS S17400 material of this study is larger than that of mature structural alloys, but is similar to other structural alloys made by additive manufacturing. (3) The tensile mechanical properties of the UNS S17400 material fabricated by selective laser melting are very different from those of wrought, heat-treated 17-4PH stainless steel. (4) The large discontinuous yielding strain in all tests resulted from the formation and propagation of Lüders bands.
\end{abstract}

Key words: additive manufacturing; hardness; Lueders bands; tensile testing; UNS 174100.

Accepted: August 12, 2014

Published: October 10, 2014

http://dx.doi.org/10.6028/jres.119.015

\section{Introduction}

Unlike traditional manufacturing processes such as turning and milling that produce parts by removing unwanted material from a larger piece, additive manufacturing (AM) processes build parts one thin layer at a time. This can be done in a variety of ways, such as sintering of powder via laser or electron beams, extrusion and deposition of polymer via a heated orifice, or selective curing of liquid photopolymers. These processes can all produce complex, high-value parts that cannot be fabricated with traditional material removal processes, can accomplish this without tooling, and with the ability to go almost directly from a digital design to part. The full vision of additive manufacturing includes using these processes to produce complex, customized metal parts for use in high-stress, mission-critical aerospace applications, such as jet engine components and turbine blades, where revolutionary, weight-saving part designs that include complex interior structures could revolutionize the manufacturing industry.

Additive manufacturing successes have received significant media attention in the popular press recently, and while additive manufacturing is already producing customized metal parts in niche applications such as dental implants [1] and demonstrating truly impressive capabilities that generate lots of societal excitement for the future of additive manufacturing [2,3], the full benefits of additive 
manufacturing are not yet realized in a widespread way across the manufacturing industry. Several technical challenges must first be overcome, including a lack of robust, design-allowable materials property data and inconsistent AM processes that result in variable materials properties [4,5].

In this paper we report some baseline mechanical property data for UNS S17400 stainless steel test specimens produced on a commercial laser-sintering machine. Specifically we examined

- the build-to-build repeatability and consistency of the tensile properties;

- the dependence of mechanical properties on the build orientation;

- the effects of post-processing heat treatment on mechanical properties, and

- the variation of mechanical properties across the build plate.

\section{Experimental Details}

\subsection{Material: UNS S17400 Stainless Steel}

The stainless steel test specimens were produced at NIST using selective laser melting (SLM), using an EOSINT M 270 laser-sintering system ${ }^{1}$ using the standard EOS build conditions that deposit layers $20 \mu \mathrm{m}$ thick in a checkerboard pattern with rotation between layers. The chemical composition of the material conforms to UNS S17400 [6,7], which is the nominal composition for for 17-4PH stainless steel, a corrosion-resistant martensitic stainless steel whose strength is increased by copper precipitation. The machine manufacturer supplied the powder. A separate manuscript summarizes relevant powder parameters [8].

Because the manufacturer recommends heat treating stainless steel parts for $1 \mathrm{~h}$ at $650{ }^{\circ} \mathrm{C}$ to relieve residual stress, some parts were heat-treated in an electrical resistance heated convection furnace in air. The specimens were contained in a nominally sealed stainless steel bag that was inserted in the cold furnace, which was then brought to temperature in about one hour.

\subsection{Tensile Testing}

\subsubsection{Specimen}

All tests used an ASTM E8 [9] subsize sheet specimen, Fig. 1. Three possible specimen orientations exist with respect to the build direction, shown in Fig. 2. Two orientations, Hv and Hp, orient the build direction perpendicular to the long axis of the specimen. In orientation "Hp" (for plan view), the build direction is normal to the plane of the specimen tab. In orientation "Hv" the build direction is normal to the side (narrowest dimension) of the specimen. Finally, in vertically oriented specimens, denoted "V," the build direction proceeds along the tensile axis of the specimen. In the vertical orientation the individual specimens are sliced from the block with electrical discharge machining (EDM). One face of the Hp orientation specimens is the final layer added, while the opposite face is produced when the specimen is cut from the build block with electrical-discharge machining. Similarly for the $\mathrm{Hv}$ orientation, one narrow side of the specimen has a finished face, while the opposite side has the remains of the support structures. Build 1 employed $\mathrm{Hv}$ orientation, while builds 2 and 3 employed the Hp orientation. The specimens were fabricated to near net shape. In build 1, it was necessary to remove the support structures from one face of the specimen, which may increase the dimensional uncertainty, and therefore the uncertainty of the reported strengths. For builds 2 and 3 we made no effort to machine or grind the faces after fabrication. Because the fabrication is so different than for wrought materials, no correspondence can be made between the traditional longitudinal, transverse, and short-transverse directions.

${ }^{1}$ Certain commercial equipment, instruments, or materials are identified in this paper in order to specify the experimental procedure adequately. Such identification is not intended to imply recommendation or endorsement by the National Institute of Standards and Technology, nor is it intended to imply that the materials or equipment identified are necessarily the best available for the purpose. 


\section{Dimensions}

G $25.40 \mathrm{~mm}$

A $\quad 31.75 \mathrm{~mm}$

W $\quad 6.35 \mathrm{~mm}$

L $\quad 101.60 \mathrm{~mm}$
Notes

Build 1: $\quad T=6.2 \mathrm{~mm}$

Builds $2 \& 3: T=3.17 \mathrm{~mm}$

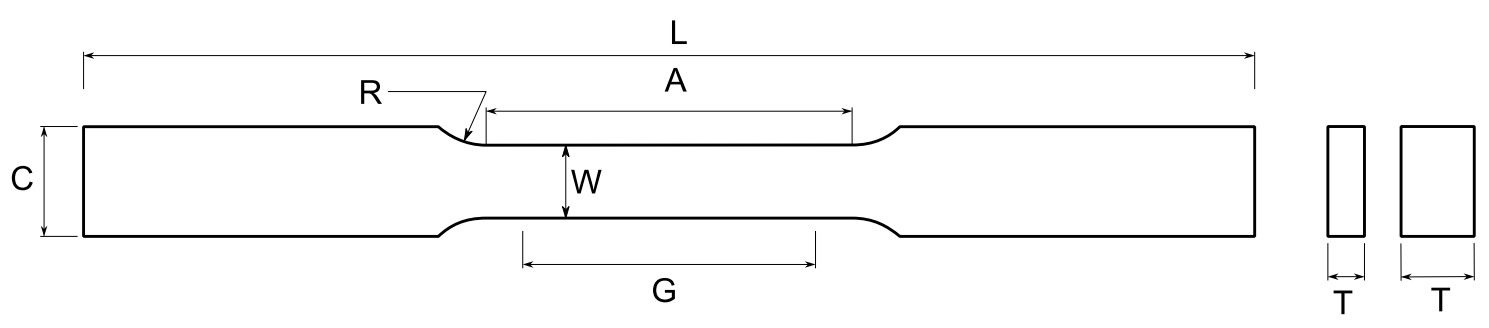

Fig 1. Tensile specimen.

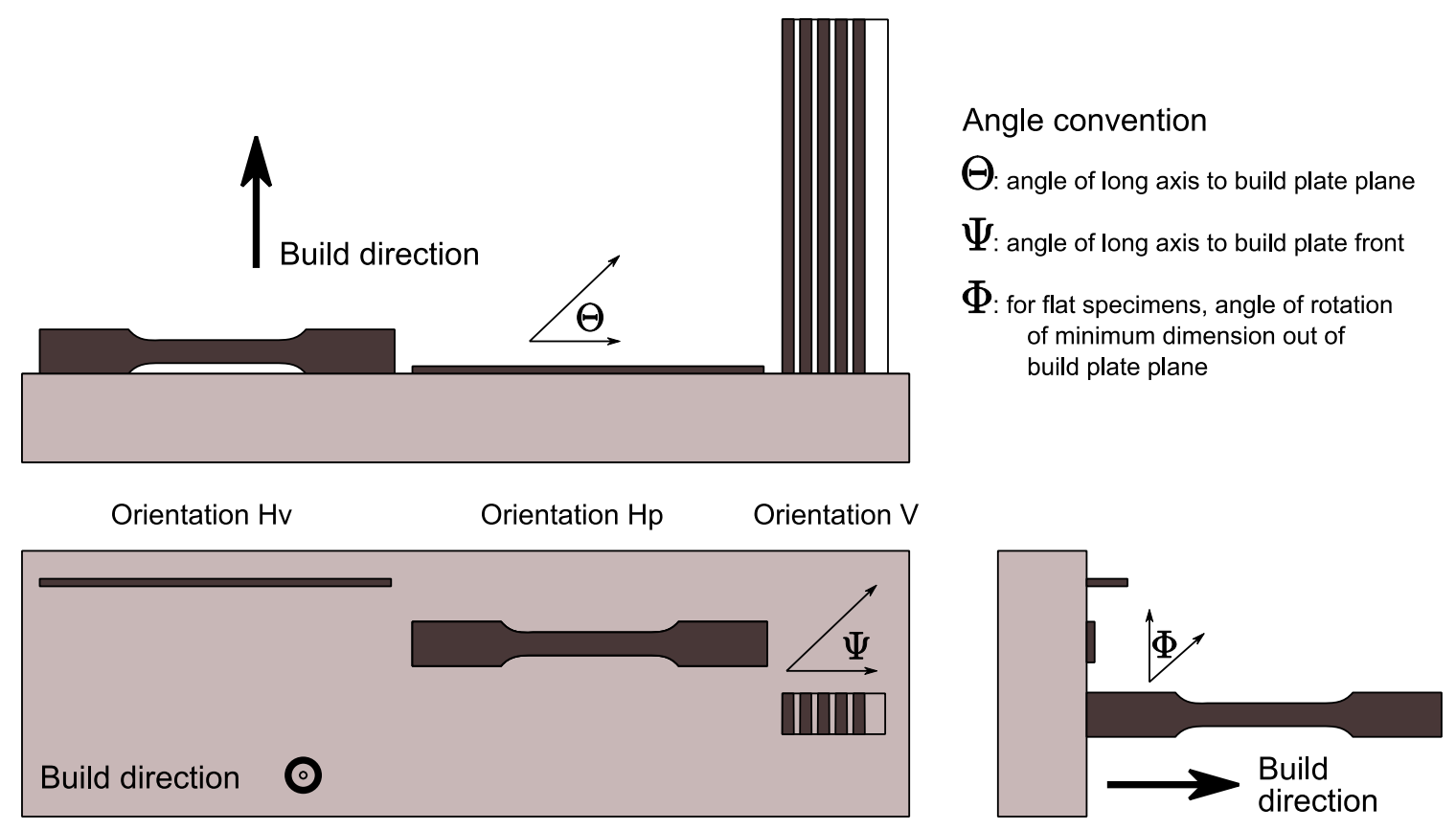

Fig. 2. Projection diagram of the three build orientations for the tensile specimens.

\subsubsection{Tensile Tests}

All tensile tests were conducted in position control in a servo-hydraulic test machine equipped with mechanical wedge grips. The extensometers met ASTM E83 [10] classification B-2. Build 1 employed an extensometer with $G=12.45 \mathrm{~mm}$, and builds 2 and 3 employed one with $G=25.4 \mathrm{~mm}$. Because the maximum measurable strain without resetting the extensometer was about $e=0.2$, the extensometer was frequently removed before the specimen reached the tensile strength. Tests followed ASTM E8, but the extension rate was not increased after yield, and the strain rate for the build 2 tests was about ten times higher than in builds 1 and 2 .

Table 1 summarizes the distribution of orientations, heat treatments across the three build rounds. 
Table 1. Number of specimens in each build round, with orientations and heat treatments.

\begin{tabular}{|c|c|c|c|c|c|c|}
\hline \multirow{3}{*}{ Build } & \multicolumn{3}{|c|}{ As deposited } & \multicolumn{3}{|c|}{ Heat-treated } \\
\hline & & & Vertical & & & Vertical \\
\hline & Нp & $\mathrm{Hv}$ & $\mathrm{V}$ & $\mathrm{Hp}$ & $\mathrm{Hv}$ & $\mathrm{V}$ \\
\hline 1 & $\mathrm{x}$ & 3 & $\mathrm{X}$ & 2 & $\mathrm{X}$ & $\mathrm{X}$ \\
\hline 2 & 6 & $\mathrm{x}$ & $\mathrm{x}$ & $\mathrm{x}$ & $\mathrm{x}$ & $\mathrm{X}$ \\
\hline 3 & 3 & $\mathrm{x}$ & 3 & 3 & $\mathrm{x}$ & 3 \\
\hline
\end{tabular}

\subsection{Hardness Testing}

Hardness tests employed the Rockwell A scale on an analog Wilson/Rockwell 3JR hardness test machine with a flat anvil. The support structures on the bottom of the test specimens were filed flat before testing Each of 16 parts received three hardness tests; the indents were spaced to $10 \mathrm{~mm}$ sided triangle in the center of the part. After every three parts (nine tests), a standard test block (51.2 \pm 1 HRA ( $k=2)$, NIST traceable) was tested to ensure repeatability. The standard test block repeatability was less than the machines indicator dial resolution, approximately 0.25 HRA. Tests were conducted both before and after heat treating at $T=650^{\circ} \mathrm{C}$ in Ar gas.

\section{Results}

\subsection{Tensile Stress-Strain Curves}

Figures 4, 5, and 6 summarize the tensile stress-strain curves from the three builds in the two orientations and two heat-treatment conditions.

The stress-strain curves of all specimens are similar. Figure 3 is a schematic diagram of the important features of each curve. Each stress-strain curve has a diffuse upper yield strength, followed by a long region of yield point elongation, also called a Lüders strain. In some specimens the structure of the strain increment associated with discontinuous yielding is quite repeatable. In addition, there is often a small discontinuity in the stress-strain curve where we suspect that a second Lüders band nucleates in the specimen tab. Because the specimen tab is only 1.5 times the gauge width, see Fig. 1, strain hardening eventually raises the strength of the gauge section above that of the tab, which forces the tab to yield as well.

Figure 4 compares as-received specimens to specimens heat-treated in air at $650{ }^{\circ} \mathrm{C}$ for $1 \mathrm{~h}$ for the three builds. Heat treating reduces all the yield strengths, but increases the tensile strength $S_{u}$. Builds 2 and 3 are similar, and different from build 1.

Figure 5 replots the stress-strain data but differentiates it by build orientation for specimens that were not heat treated. Only build 3 contains vertically oriented specimens. The discontinuous yielding in build 2 Vertical specimens is longer, and its structure differs from the horizontal specimens of all three builds.

Figure 6 shows the orientation dependence for heat-treated specimens. Heat treatment reduces the discontinuous yielding region in the vertical specimens, but does not change the general shape.

Appendix A contains plots for all the stress-strain curves individually by build, orientation, and heat treatment for comparison.

There is evidence that plastic deformation causes a change in the phases present in the material. The undeformed material, in both the as-deposited and heat-treated conditions is non-magnetic. After deformation, the test specimens were strongly ferromagnetic.

The low-strain structure of the stress-strain curve in the discontinuous yielding region is caused by the formation and propagation of two Lüders bands, which nucleate at the ends of the gauge length and propagate until they meet in the center of the specimen. They also create the yield point behavior, Fig. 3. During the formation and propagation of the Lüders bands, the strain in the gauge section of the specimen is inhomogeneous. All the deformation is concentrated in the narrow band, and rest of the gauge section is still has not plastically deformed. Section 4.1 analyzes this behavior in greater detail. 


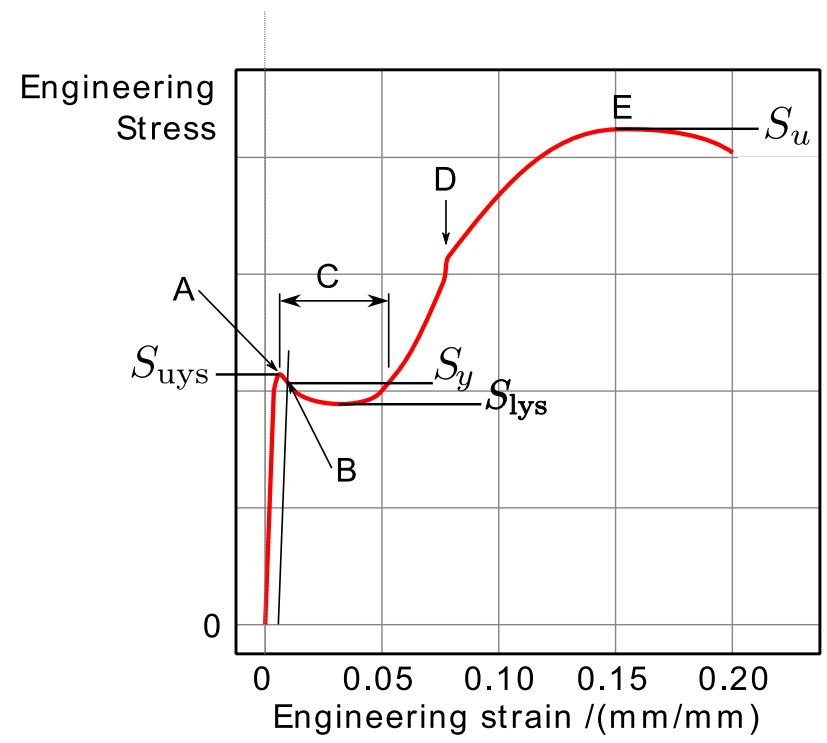

Key:

A: Upper yield strength $\mathrm{S}_{\text {uys }}$

B: $0.2 \%$ offset yield strength $S_{y}$

C: Lueders band/discontinuous yielding

D: Lueders band nucleates in specimen head

$\mathrm{E}$ : Tensile strength $\mathrm{S}_{\mathrm{u}}$

Fig. 3. Schematic diagram of the stress-strain curve.

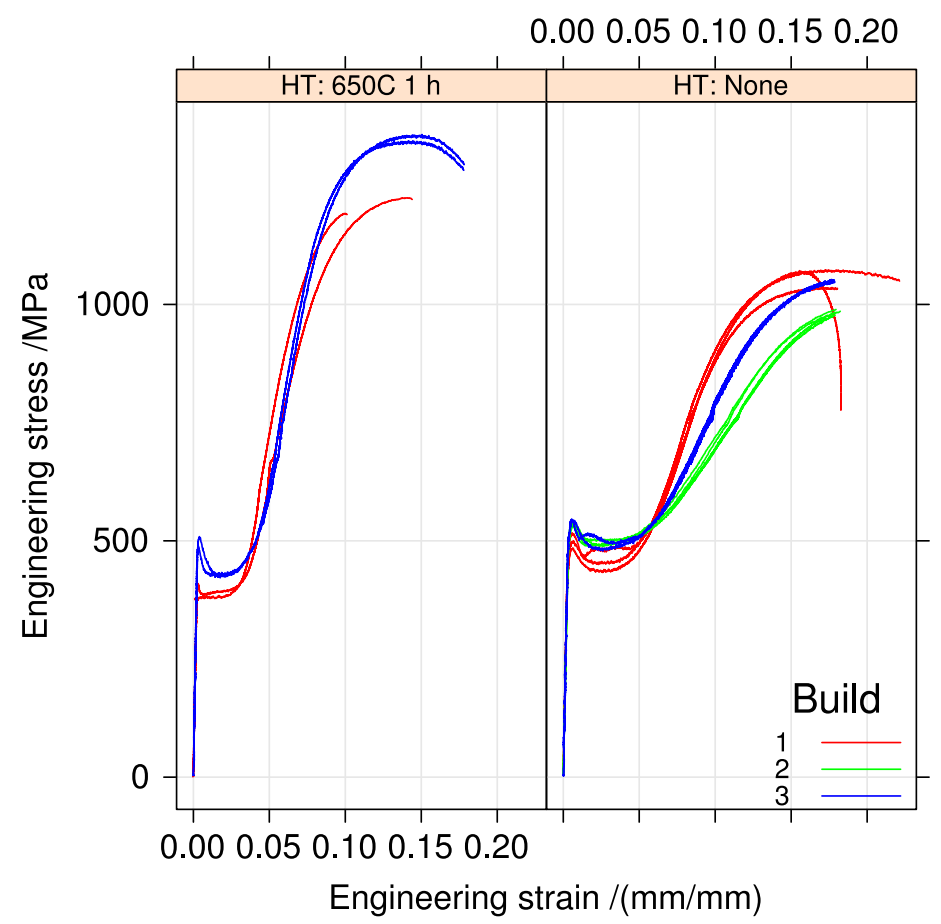

Fig. 4. Tensile stress-strain curves for the three builds, horizontal orientation, separated by heat treatment. 


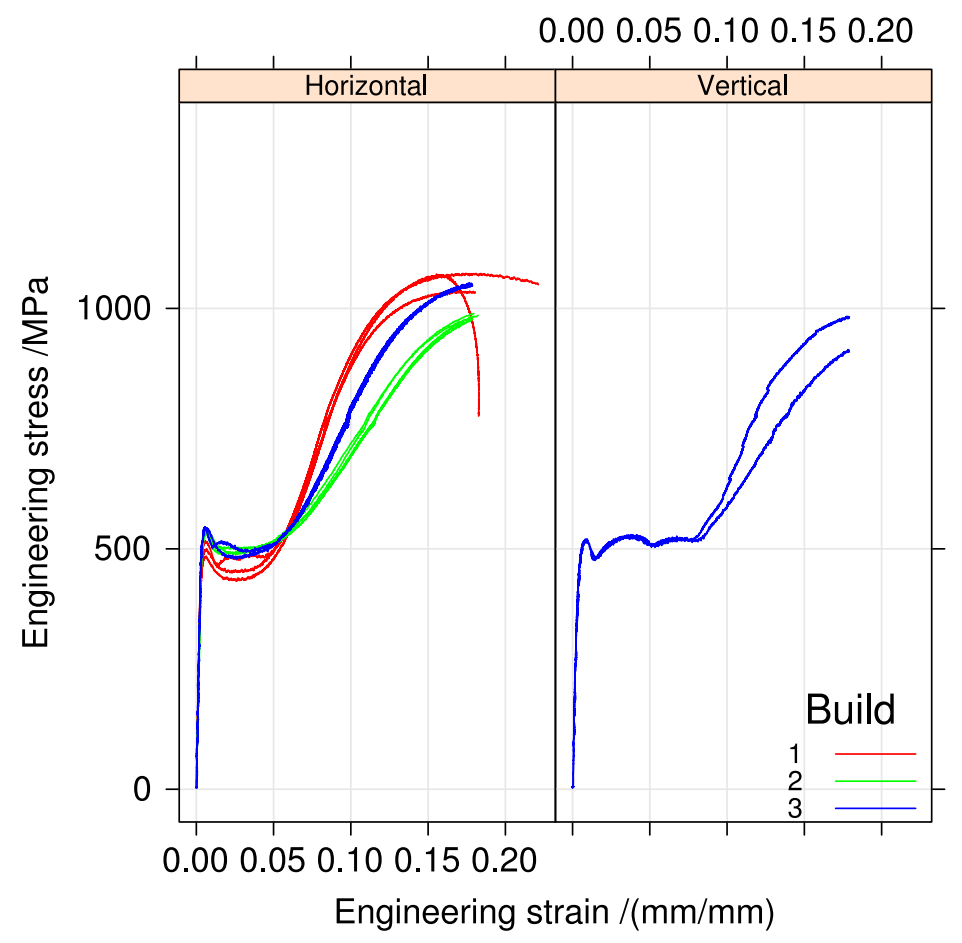

Fig. 5. Tensile stress-strain curves for the builds, separated by orientation, for the un-heat-treated condition.

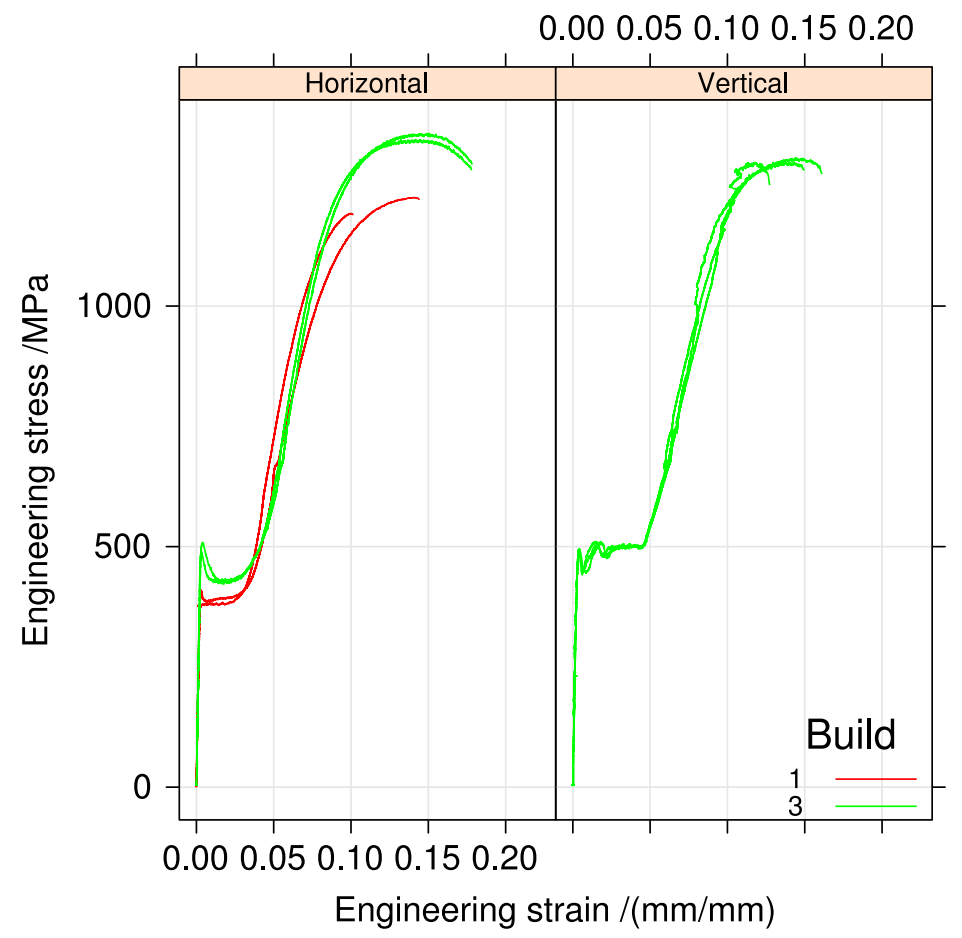

Fig. 6. Tensile stress-strain curves for the builds, separated by orientation, for the heat-treated condition. 


\subsection{Hardness}

Figure 7 plots the average hardness as a function of position on the build plate, before and after heat treatment. The hardness disks were $d=40 \mathrm{~mm}$ diameter spaced on $50 \mathrm{~mm}$ centers in both $X$ and $Y$, and the centers of the outer rows are also $50 \mathrm{~mm}$ from the build-plate edge. In the plot the recoater enters from the $X=4$ column. An analysis of variance demonstrated that there is no statistically significant difference at the $5 \%$ confidence level between the mean hardnesses of the unheat-treated specimens. A similar analysis demonstrated that the hardnesses of specimens 4, 5, 7, 10, and 11 are significantly different from the mean hardness. Figure 8 shows that, even though the hardesses of the un-heat-treated specimens are not distinguishable, a negative correlation exists between the initial hardness and the change in hardness caused by the stress-relief heat treatment at $650{ }^{\circ} \mathrm{C}$. Figure 9 plots the data of Fig. 8 as a function of position on the build plate. No obvious relation between hardness change and position exists. Table 2 summarizes the numerical data of Figs. 7, 8, and 9.

Table 2. Results of all hardness tests.

\begin{tabular}{cccc}
\hline Position & \multicolumn{3}{c}{ Heat Treatment } \\
$(X, Y)$ & Nart & \multicolumn{1}{c}{ HRA } & $650{ }^{\circ} \mathrm{C} 1 \mathrm{~h}$ \\
\hline$(1,1)$ & 1 & $53.9,59,59$ & $70,71.3,71.1$ \\
$(2,1)$ & 2 & $56,59,58.8$ & $67.1,67.5,70.2$ \\
$(3,1)$ & 3 & $55.1,56.9,56.8$ & $73,70.5,69.9$ \\
$(4,1)$ & 4 & $57.8,55.4,57.9$ & $73.5,71.5,70.6$ \\
$(1,2)$ & 5 & $56.9,54.9,59$ & $66.3,68.6,68.2$ \\
$(2,2)$ & 6 & $55.5,58.4,55.5$ & $71.6,68.5,70.8$ \\
$(3,2)$ & 7 & $61.6,55,58.5$ & $66.4,69.4,67.2$ \\
$(4,2)$ & 8 & $55.7,56.6,58$ & $69,69.4,73.9$ \\
$(1,3)$ & 9 & $56.1,57.8,55.1$ & $71.5,71.9,70.3$ \\
$(2,3)$ & 10 & $56.9,54.9,57.8$ & $67.6,66.2,66.8$ \\
$(3,3)$ & 11 & $60.5,58.1,57$ & $67.5,67.7,65.7$ \\
$(4,3)$ & 12 & $56.9,58.5,56.9$ & $67.9,68.3,72.2$ \\
$(1,4)$ & 13 & $57.5,55.1,55.3$ & $70.4,69.6,71.4$ \\
$(2,4)$ & 14 & $59.5,56.8,56.9$ & $69.6,69.9,72.2$ \\
$(3,4)$ & 15 & $59.1,57,57.2$ & $68.3,70.6,72.2$ \\
$(4,4)$ & 16 & $57.5,58.2,57.1$ & \\
\hline
\end{tabular}

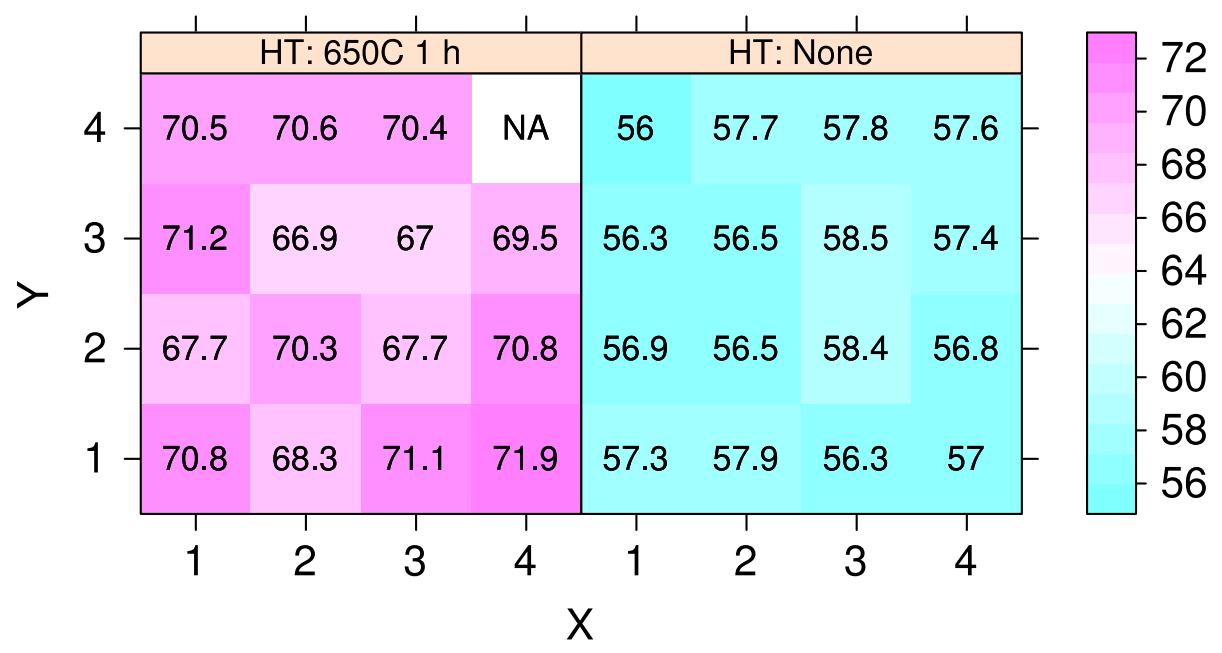

Fig. 7. Hardness map for the sixteen hardness specimens before and after heat treatment, in units of HRA. Position $(1,1)$ corresponds to part 1 at the front of the machine, and position $(4,4)$ corresponds to part 16 . The recoater enters from the $X=4$ column. Color key shows hardness in units of HRA points. 


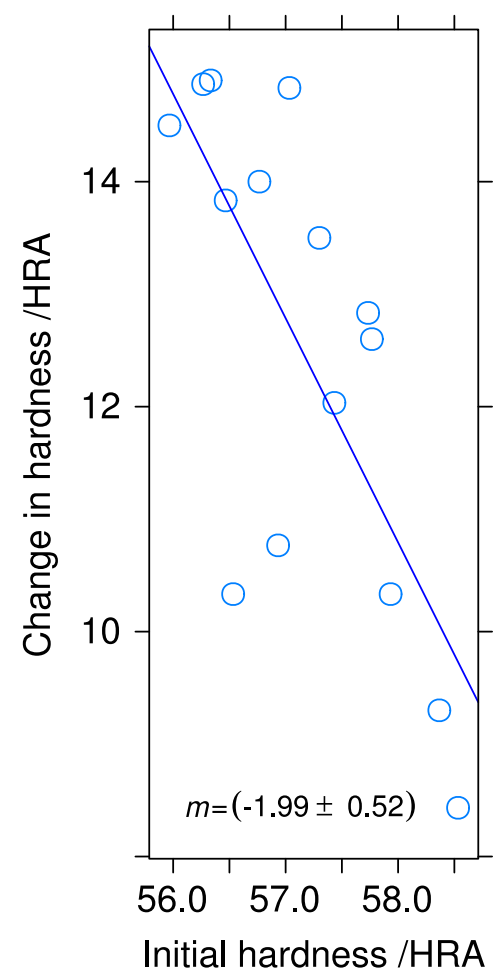

Fig. 8. Change in hardness, in HRA points, after heat treating, as a function of initial hardness for the test specimens.

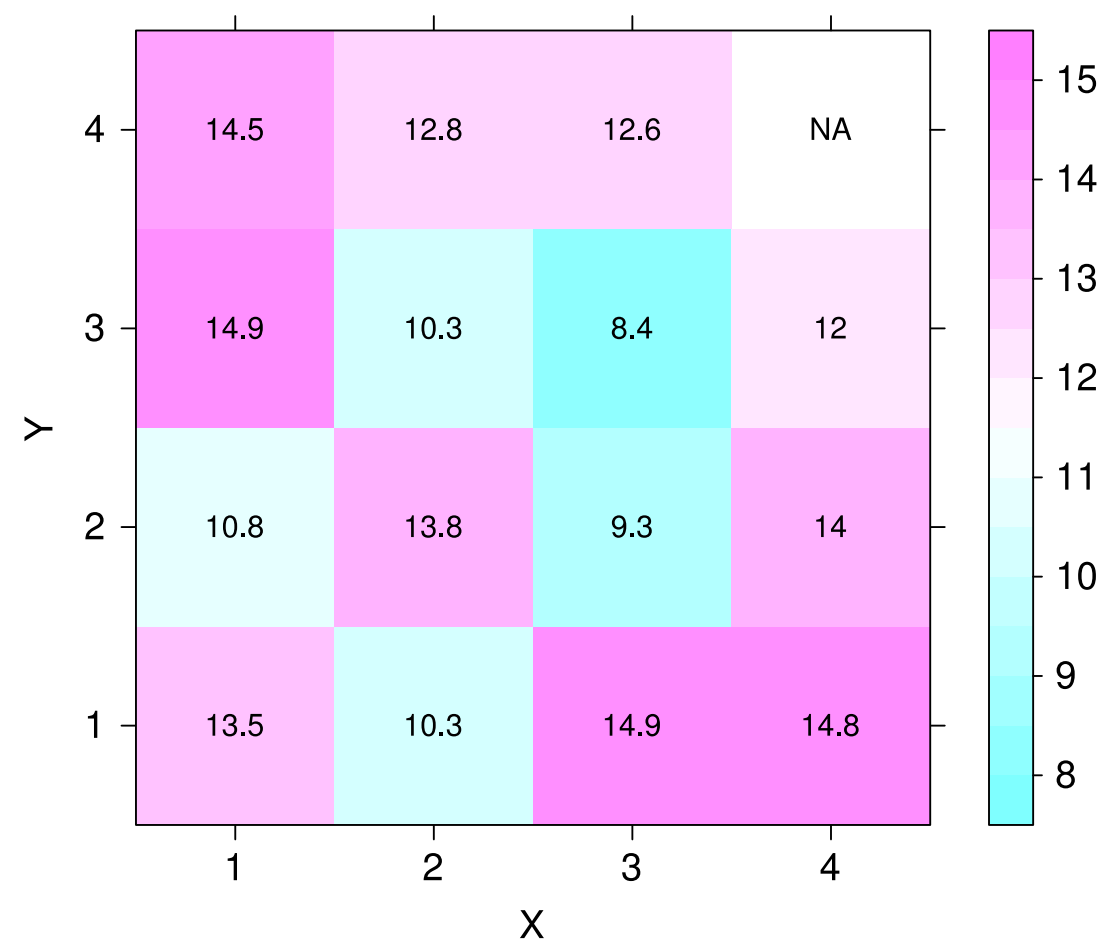

Fig. 9. Change in hardness after heat treating as a function of position on the build plate. Color key shows the hardness change in units of HRA points. 


\subsection{Summary Results}

Table 3 summarizes the tensile data. Figures 10 and 11 plot the summary data for $0.2 \%$ offset yield strength $S_{y}$ and tensile strength $S_{u}$, by build and by orientation.

Table 3. Summary data for the tensile tests: $S_{y}=0.2 \%$ offset yield strength; strength units are MPa and strain rate units are $\mathrm{mm} / \mathrm{mm} / \mathrm{s}$.

\begin{tabular}{ccccclll}
\hline Build & $S_{y}$ & $S_{\text {uys }}$ & $S_{\text {lys }}$ & $S_{u}$ & $d e / d t$ & Heat Treatment & Orientation \\
\hline 1 & 491 & 498 & 457 & 1071 & $6.7 \mathrm{E}-05$ & HT: None & Horizontal \\
1 & 479 & 483 & 437 & 1034 & $6.6 \mathrm{E}-05$ & HT: None & Horizontal \\
1 & 509 & 515 & 468 & 1068 & $6.6 \mathrm{E}-05$ & HT: None & Horizontal \\
1 & 379 & 379 & 379 & 1192 & $6.5 \mathrm{E}-05$ & HT: 650C $1 \mathrm{~h}$ & Horizontal \\
1 & 392 & 408 & 387 & 1225 & $6.5 \mathrm{E}-05$ & HT: 650C $1 \mathrm{~h}$ & Horizontal \\
2 & 531 & 531 & 489 & 999 & $8.3 \mathrm{E}-04$ & HT: None & Horizontal \\
2 & 526 & & & 993 & $8.3 \mathrm{E}-04$ & HT: None & Horizontal \\
2 & 514 & & & 986 & $8.3 \mathrm{E}-04$ & HT: None & Horizontal \\
2 & 536 & & & 1004 & $8.3 \mathrm{E}-04$ & HT: None & Horizontal \\
2 & 532 & & & 1001 & $8.3 \mathrm{E}-04$ & HT: None & Horizontal \\
2 & 531 & & & 1006 & $8.3 \mathrm{E}-04$ & HT: None & Horizontal \\
3 & 475 & 489 & 425 & 1343 & $9.1 \mathrm{E}-05$ & HT: 650C $1 \mathrm{~h}$ & Horizontal \\
3 & 542 & 550 & 500 & 1068 & $9.1 \mathrm{E}-05$ & HT: None & Horizontal \\
3 & 501 & 509 & 429 & 1357 & $9.1 \mathrm{E}-05$ & HT: 650C $1 \mathrm{~h}$ & Horizontal \\
3 & 537 & 542 & 483 & 1054 & $9.1 \mathrm{E}-05$ & HT: None & Horizontal \\
3 & 435 & 507 & 436 & 1358 & $9.1 \mathrm{E}-05$ & HT: 650C $1 \mathrm{~h}$ & Horizontal \\
3 & 545 & 545 & 496 & 1055 & $9.1 \mathrm{E}-05$ & HT: None & Horizontal \\
3 & 476 & 494 & 445 & 1296 & $9.1 \mathrm{E}-05$ & HT: 650C $1 \mathrm{~h}$ & Vertical \\
3 & 496 & 519 & 482 & 996 & $9.1 \mathrm{E}-05$ & HT: None & Vertical \\
3 & 489 & 493 & 447 & 1305 & $9.1 \mathrm{E}-05$ & HT: 650C $1 \mathrm{~h}$ & Vertical \\
3 & 495 & 516 & 480 & 994 & $9.1 \mathrm{E}-05$ & HT: None & Vertical \\
3 & 484 & 487 & 449 & 1294 & $9.1 \mathrm{E}-05$ & HT: 650C $1 \mathrm{~h}$ & Vertical \\
3 & 491 & 516 & 478 & 947 & $9.1 \mathrm{E}-05$ & HT: None & Vertical \\
\hline
\end{tabular}

\section{Analysis}

\subsection{Comparison to Accepted Values}

Figure 12 compares the stress-strain behavior for the UNS S17400 stainless steel in the horizontal orientation for the as-fabricated and heat-treated condition to the corresponding curves reported by the the MMPDS [12], the manufacturer [11], and one literature report from Facchini et al. [13] that used the manufacturer's material and fabrication process. The tensile properties of the UNS S17400 stainless steel are completely different from the accepted values for 17-4PH stainless steel from the MMPDS for all heat treatments. The yield strengths of the UNS S17400 stainless steel are much lower, and the material exhibits extensive yield point elongation absent in 17-4PH stainless steel.

Figure 12 also shows that the UNS S17400 stress-strain curves from three sources are similar, but not identical. Facchini identified the origin of the difference between the "typical" values [12] for 17-4PH stainless steel and the material fabricated by selective laser melting. Wrought $17-4 \mathrm{PH}$ stainless steel is supplied by the mill as a fully martensitic material, which is then heat treated to form copper precipitates, which increase the strength. In contrast, Facchini et al.’s [13] analysis showed that the as-fabricated UNS S17400 stainless steel was 70 percent mass fraction metastable austenite, which transformed to the martensite phase during tensile deformation. The material of our study is similar to that of Facchini et al. [13], in that the as-fabricated material is not magnetic, and therefore not martensitic, but after deformation 


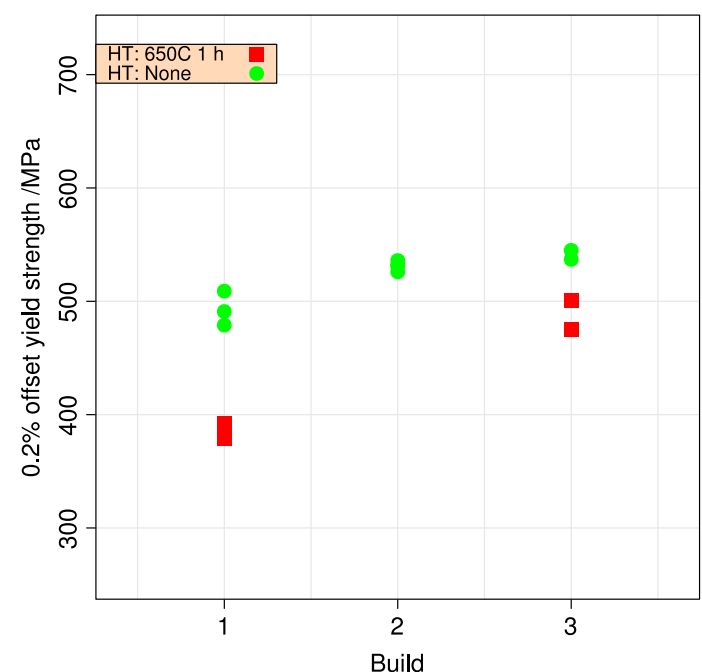

(a) $0.2 \%$ offset yield strength $S_{y}(0.2 \%$ offset)

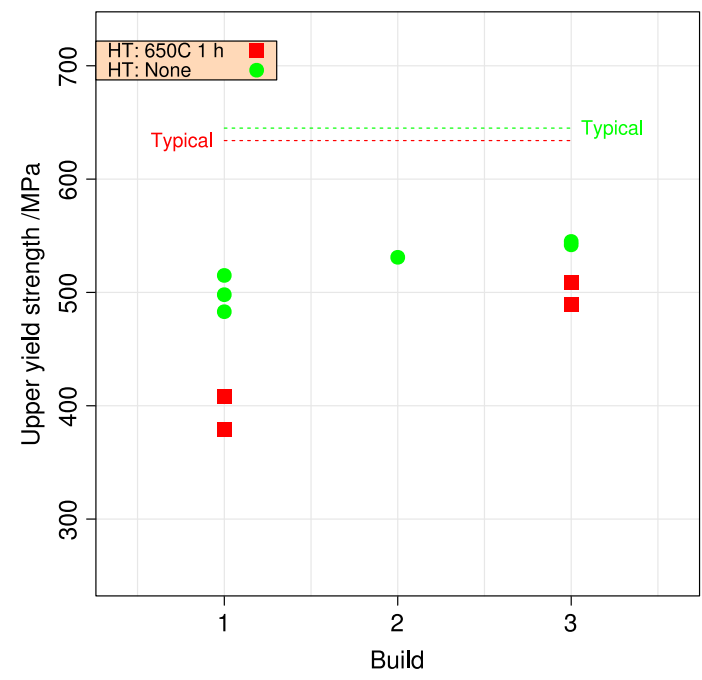

(c) Upper yield strength $S_{\text {uys }}$

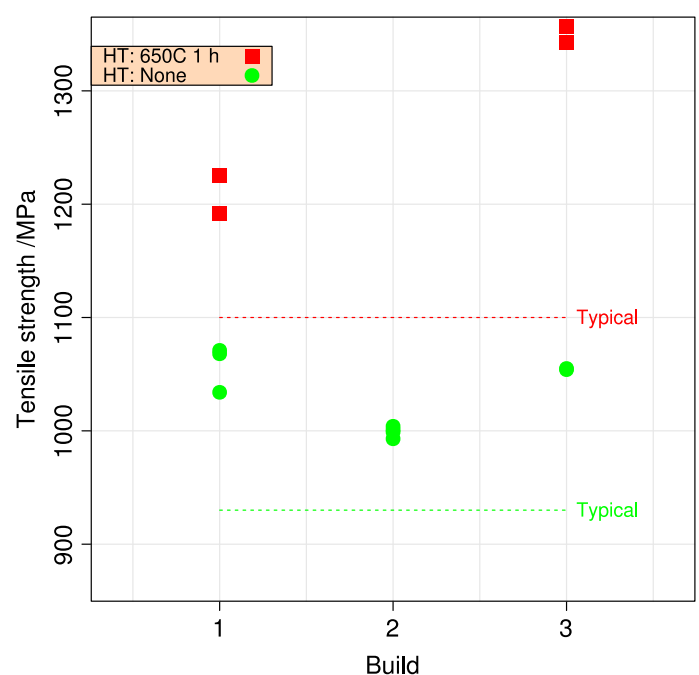

(b) Tensile strength, $S_{u}$

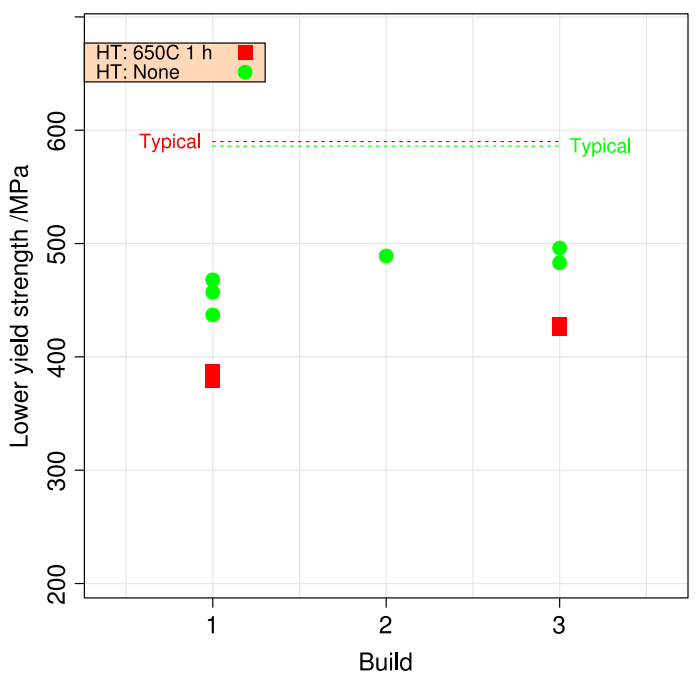

(d) Lower yield strength $S_{\text {lys }}$

Fig. 10. Repeatability of the yield and tensile strengths from three builds, horizontal orientation, separated by heat treatment. Horizontal lines indicate manufacturer's [11] typical values. (a) $0.2 \%$ offset yield strength $S_{y}\left(0.2 \%\right.$ offset) (b) tensile strength $S_{u}$, (c) upper yield strength $S_{\text {uys }}$, and (d) lower yield strength $S_{\text {lys. }}$. 


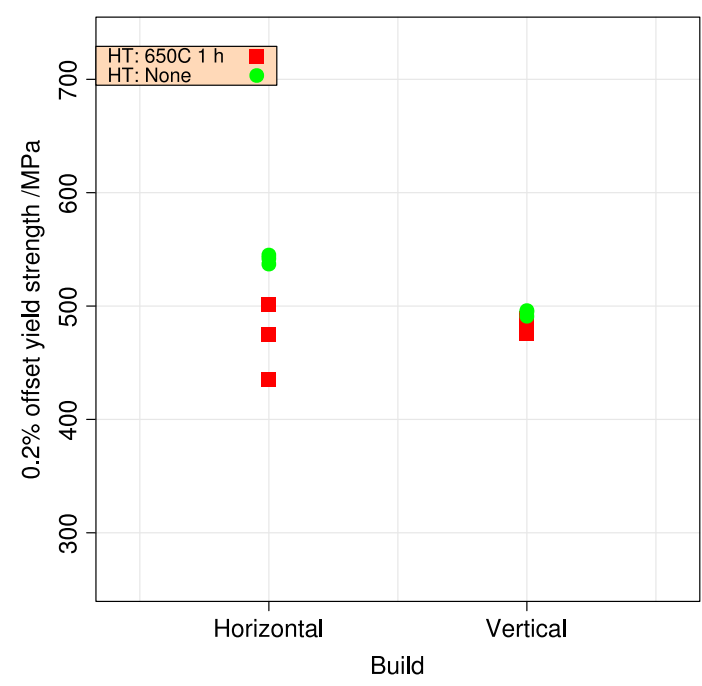

(a) $0.2 \%$ offset yield strength $S_{y}(0.2 \%$ offset)

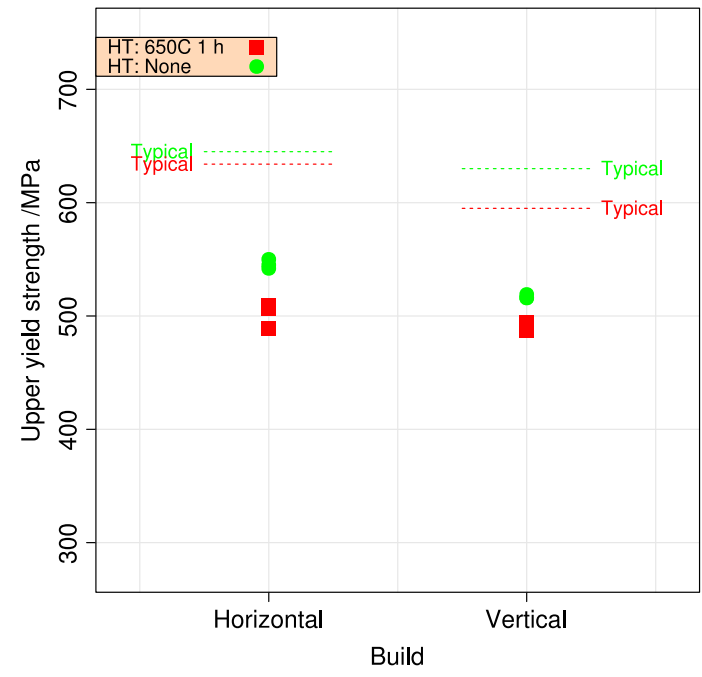

(c) Upper yield strength $S_{\text {uys }}$

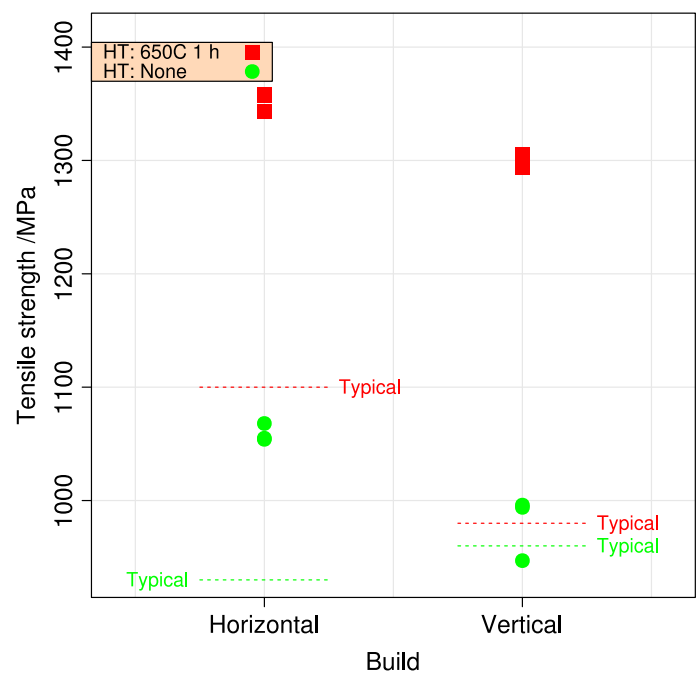

(b) Tensile strength, $S_{u}$

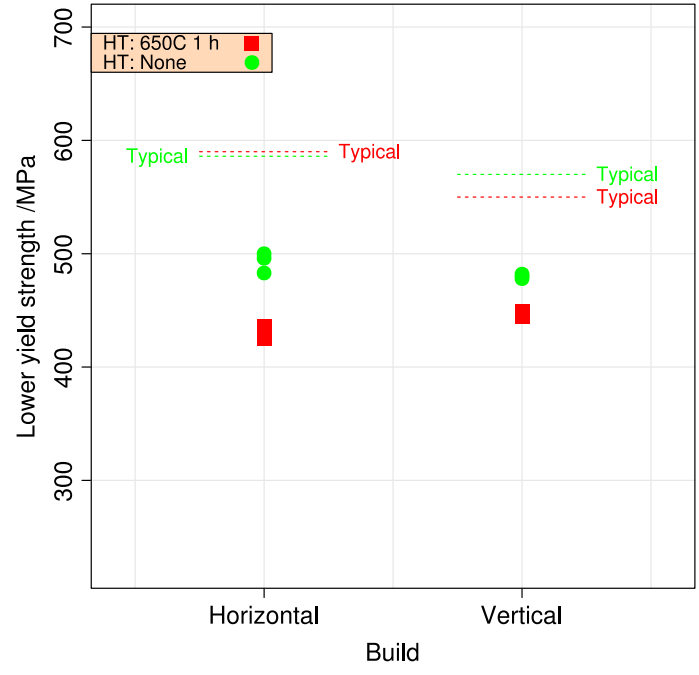

(d) Lower yield strength $S_{\text {lys }}$

Fig. 11. Repeatability of the yield and tensile strengths for UNS S17400 stainless steel build 2, for horizontal and vertical orientations and two heat treatments. (a) $0.2 \%$ offset yield strength $S_{y}\left(0.2 \%\right.$ offset) (b) tensile strength $S_{u}$, (c) upper yield strength $S_{\text {uys, }}$, and (d) lower yield strength $\mathrm{S}_{\mathrm{lys}}$. 


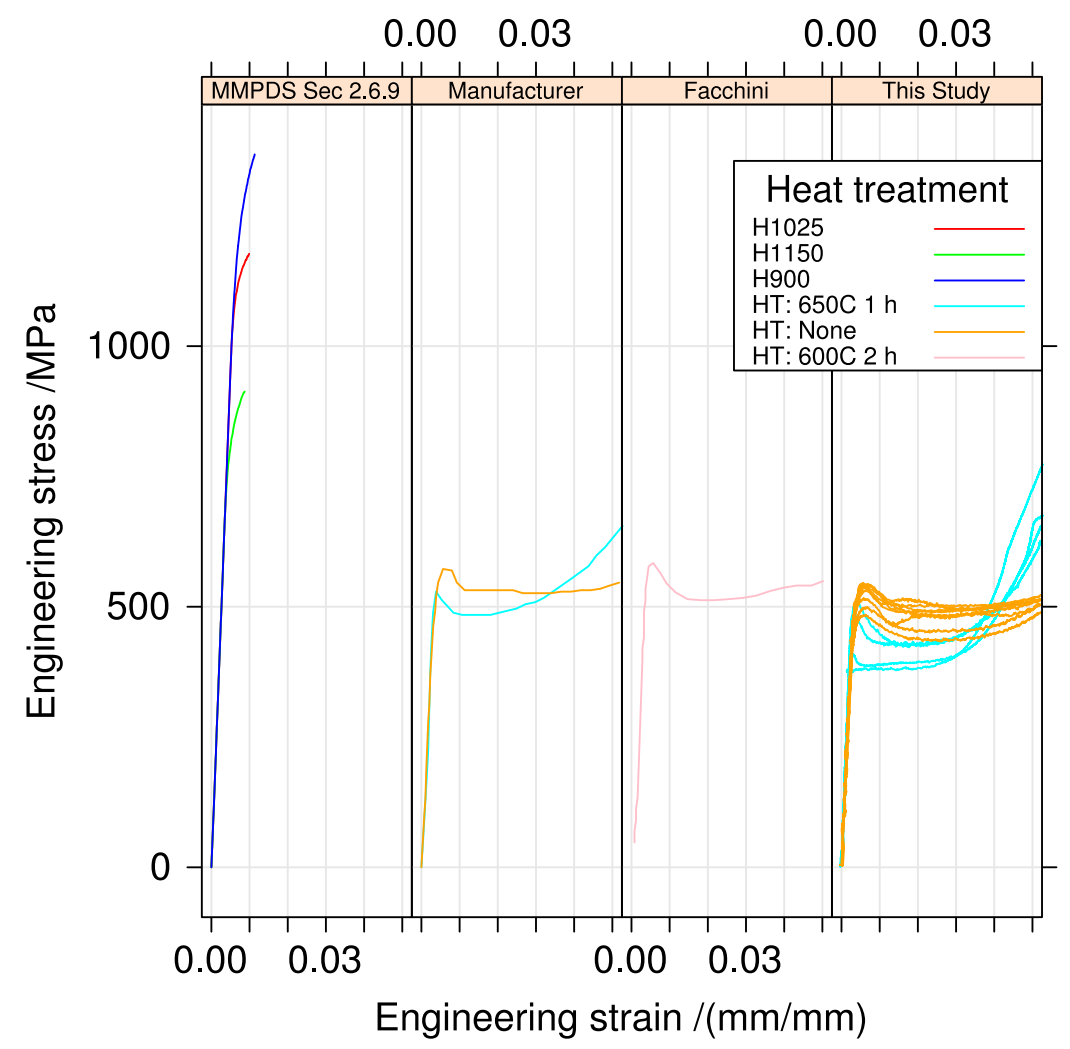

Fig. 12. Comparison of UNS S17400 stress-strain curves to accepted behavior. Data sources: MMPDS Sec. 2.6.9 [12], Manufacturer [11], Facchini [13].

the specimens are strongly ferromagnetic. The deformation-induced austenite-to-martensite transformation is common in austenitic stainless steels and has been studied extensively $[14,15]$. Because of the different phases, it is inappropriate to refer to the UNS S17400 material as 17-4PH stainless steel, even though the powder is chemically consistent with the composition of 17-4PH SS. The UNS S17400 stainless steel fabricated by selective laser melting contains different phases-significant quantities of retained austenite as opposed to all martensite. In addition no literature sources have definitively identified $\mathrm{Cu}$ precipitates in the material made by selective laser melting.

\subsection{Expected Variability of Mechanical Properties}

\subsubsection{Strength}

The powder supplier reports [16] minimum and typical properties for the upper and lower yield strengths and the tensile strength. In addition, the typical properties are reported with uncertainties of $\pm 50 \mathrm{MPa}$. The data sheet does not explain what this uncertainty represents, however. The specification sheet is clear that the manufacturer guarantees neither typical nor minimum properties.

Variability in mechanical properties of structural alloys comes in three forms.

1. variability in expected values for an individual alloy in a given form produced by many suppliers

2. variability introduced by differences in test protocol between the laboratories that evaluated the property

3. spatial or temporal variability within a given production run of material. In additive manufacturing, this variability might be between different areas on the build plate or between successive builds of material. 
The first two examples do not represent intrinsic properties of the material. Instead, the first represents a complex combination of material processing and user expectations for materials that are often delivered to standards that specify required mechanical properties. The second represents the variability that is introduced by the attempt to measure the property itself.

Figures 13 and 14 compare variability for yield and tensile strengths of the UNS S17400 material of this study do that for

- $\quad$ aerospace and pressure-vessel ferrous wrought structural alloys, [12,17],

- $\quad$ structural steels for buildings [18-21],

- $\quad$ measurements made to evaluate the within-lab and between-lab variability of test technique $[9,22]$, and

- $\quad$ two ferrous alloys made by additive manufacturing [23,24].

In the panels, the variability is expressed as the coefficient of variation, $V_{r}$, defined as the standard deviation of the property normalized to its mean value.

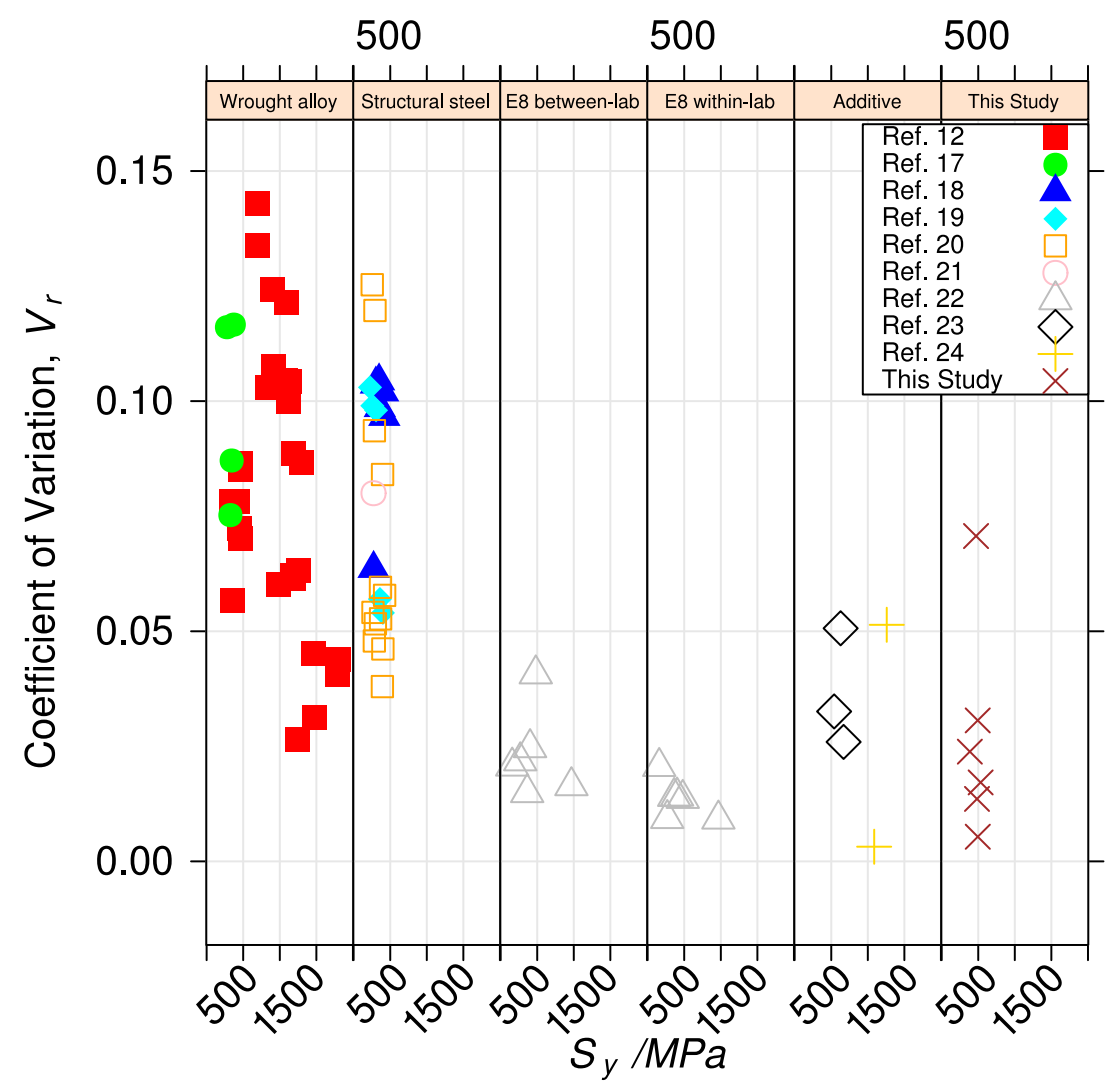

Fig. 13. Coefficient of variation of yield strength for various alloys. 


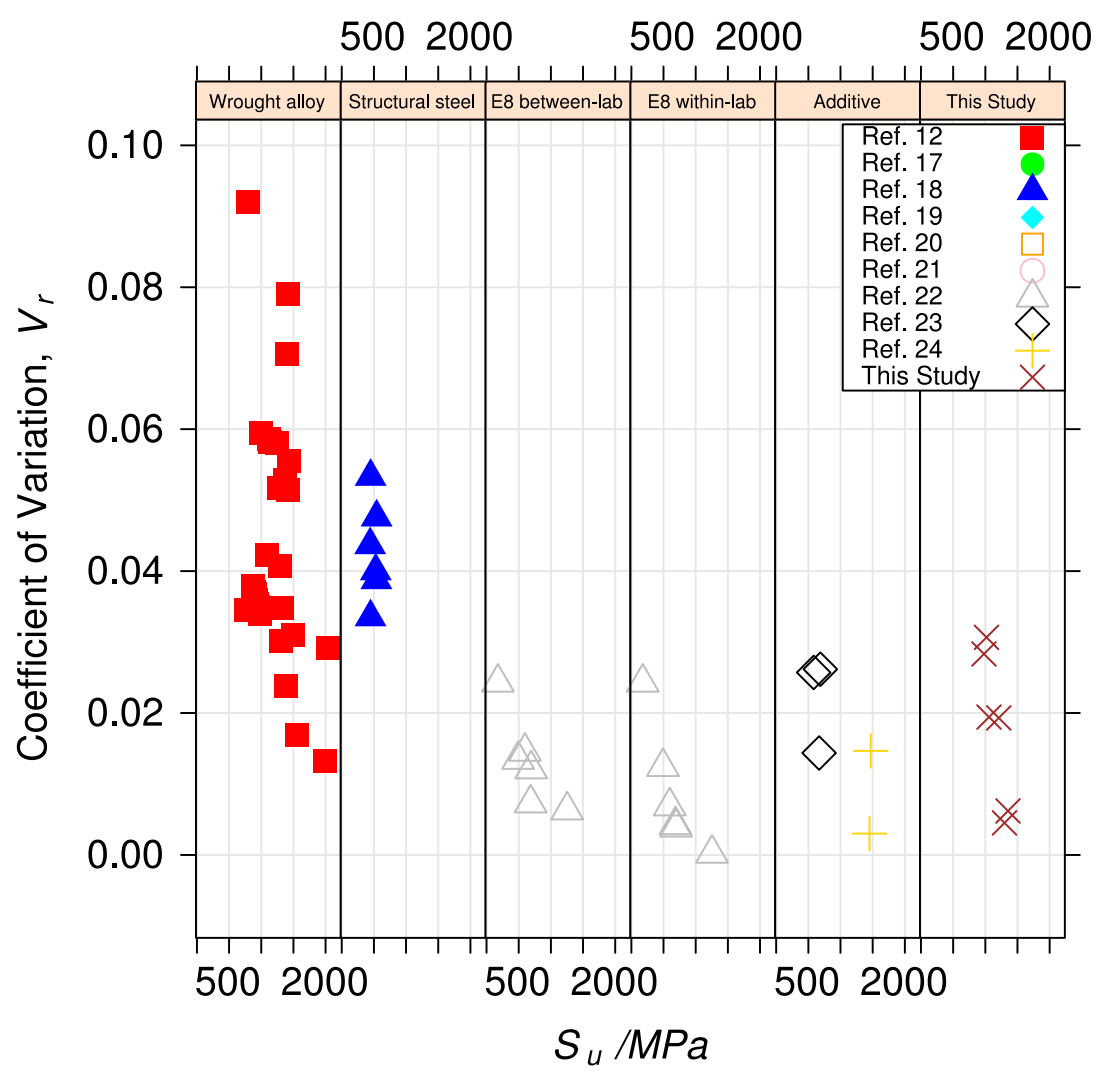

Fig. 14. Coefficient of variation of tensile strength for various alloys.

The panel labeled "E8 within-lab" contains data [9] that was used to evaluate the variability of the ASTM E8 uniaxial tension test within a single, competent testing laboratory, using homogeneous material. Ideally, the coefficient of variability (average $V_{r}=0.013$ ), summarized in Table 4 represents only the contribution of the test technique itself. The variability of the material of this study and the two other ferrous alloys made by additive manufacturing are about twice as large, which indicates that some build-tobuild variability exists.

The panels labeled "Wrought alloy" and "Structural steel” represent the acceptable variability for conventional mature structural engineering alloys (average $V_{r}=0.08$ also summarized in Table 4). This variability encompasses all of the within- and between-lab variability, as well as the differences in manufacturing processes.

Table 4. Coefficient of variation for various alloy classes.

\begin{tabular}{lcc}
\hline Class & $V_{r}\left(S_{y}(0.2 \%\right.$ offset $\left.)\right)$ & $V_{r}\left(S_{u}\right)$ \\
\hline Wrought alloy & 0.080 & 0.044 \\
Structural steel & 0.079 & 0.043 \\
E8 between-lab & 0.023 & 0.013 \\
E8 within-lab & 0.013 & 0.009 \\
Additive & 0.033 & 0.017 \\
This Study & 0.027 & 0.018 \\
\hline
\end{tabular}




\subsubsection{Orientation Effects}

Metal fabrication processes rarely produce isotropic materials. Rolling a plate or bar produces a material where the strengths are reasonably equal in directions longitudinal and transverse to the rolling direction. The elongation to failure in the transverse directions can be significantly lower than in the longitudinal direction. In additive manufacturing, it is likely that the mechanical properties in the build direction will differ from those in the plane of the build, much in the same way that the directionality of rolling produces metals with anisotropic properties. Figures 15 and 16 compare the tensile and yield strengths of the material of this study to other ferrous alloys [23-27] made by additive manufacturing and selected ferrous structural alloys from the MMPDS [12]. The normalized strengths, $R$, are plotted as a function of the angle, $\Theta$, of the specimen axis with respect to the build plane, see Fig. 2 . The normalizing factor is the strength measured for an in-plane specimen ( $\Theta=0, \Psi=0$ ), so at least one data point is $R=1$. The anisotropy of the UNS S17400 is similar to other structural alloys made by additive manufacturing, and both sets are much larger than the anisotropy expected for mature structural alloys. The data for wrought structural alloys represent longitudinal $(\Theta=0, \Psi=0)$ and long-transverse $(\Theta=0, \Psi=90)$ orientations. Short-transverse data $(\Theta=90)$ are not available for these alloys.

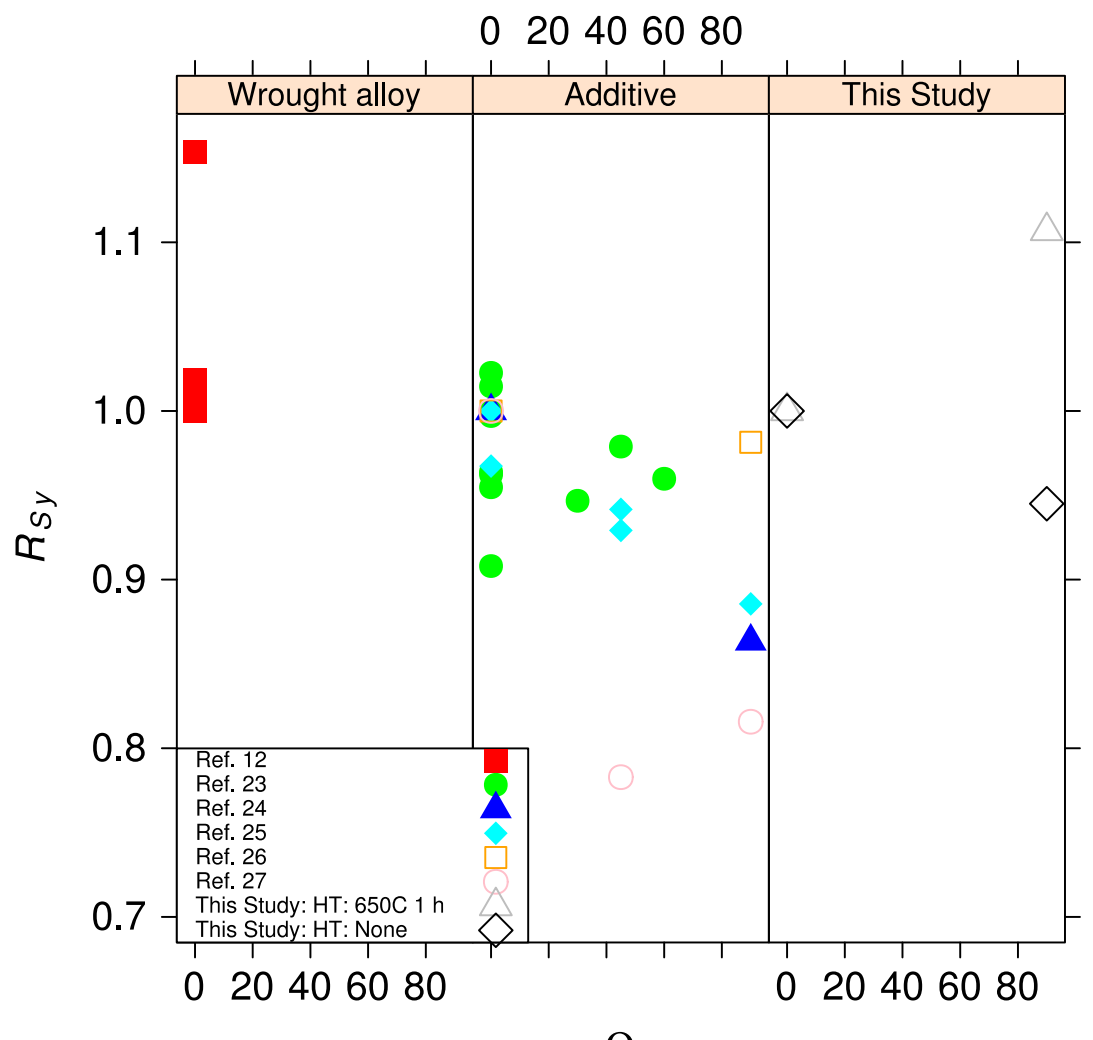

$\Theta$

Fig. 15. Normalized yield strength as a function angle, $\Theta$, out of the specimen build plane. 


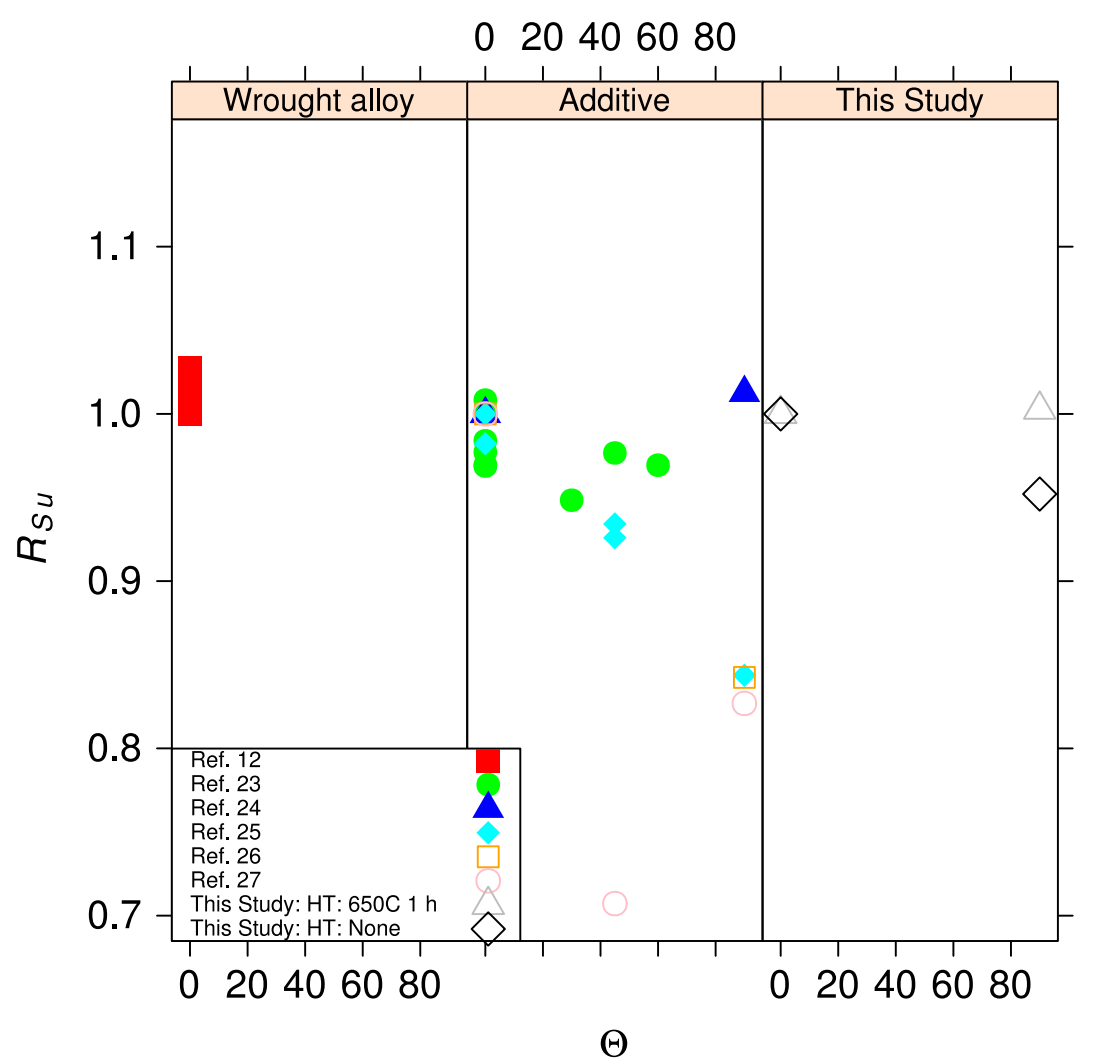

Fig. 16. Normalized tensile strength as a function angle, $\Theta$, out of the specimen build plane.

\subsection{Stress-Strain Artifacts}

The stress-strain curves exhibit several artifacts that are known $[28,29]$ to be created by the interaction of the discontinuous yielding or Lüders bands, the specimen geometry and surface finish, and the geometry of the extensometer. To demonstrate these artifacts, we employed digital image correlation (DIC) to map the specimen axial strain in the gauge section of a build 3 vertical heat-treated specimen. Figure 17 is a montage of images of the gauge length of the specimen at various points on the stress-strain curve. Overlaid on those images are the computed axial true strains, $e_{y y}$. The top row of images shows the lowstrain behavior, primarily in the region of yield point elongation. The lower row shows the behavior plotted in an expanded scale. Three images are plotted in both rows for comparison. The knife edges of the extensometer are located approximately at the ends of the region where the strains are mapped. The plot in the upper right locates the images on the stress-strain curve. It plots the engineering strain reported by the extensometer of the mechanical test system as well as the engineering strain evaluated at a point near the eventual failure location using DIC. The top row of images shows the propagation of the Lüders bands, first from the top of the specimen (Image 279) and then from the bottom of the specimen (Image 353). During the region of discontinuous yielding the center section of the specimen gauge length is strained elastically, but at each ends, the bands have produced a plastic strain $e \approx 0.05$. The bands meet sometime before Image 415, and for a while, the strain in the gauge length is relatively uniform. Necking begins around Image 991, and is quite severe by Image 1066. The strains in the neck approach $e=0.2$, while the strains outside the neck are only half as large. Even in Image 549, the strains in the gauge length are not uniform, and this non-uniformity manifests itself by the divergence between the extensometer-measured strain, which is essentially the average along the entire gauge length, and the DIC-measured strain, which is evaluated near the eventual fracture location. 

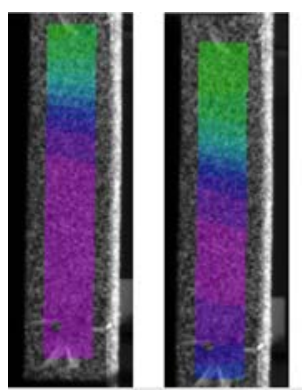

279
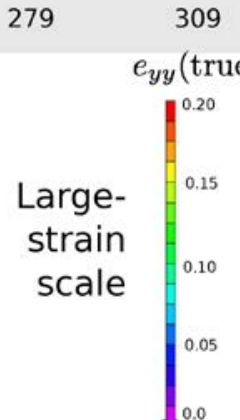

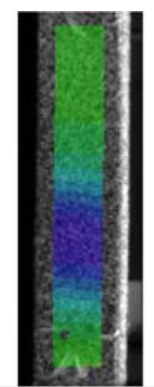

353

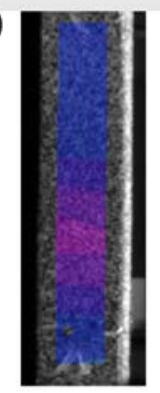

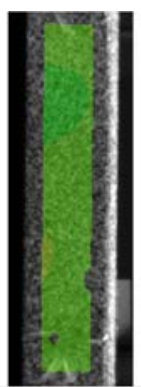

415

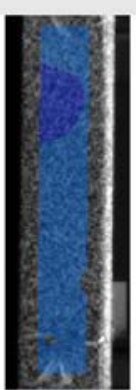

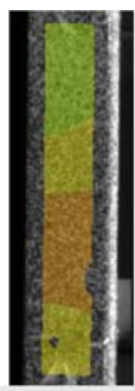

549

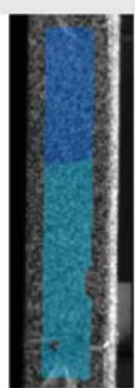

$e_{y y}$ (true)

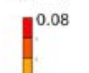

$-0.06$

Small-

strain

scale
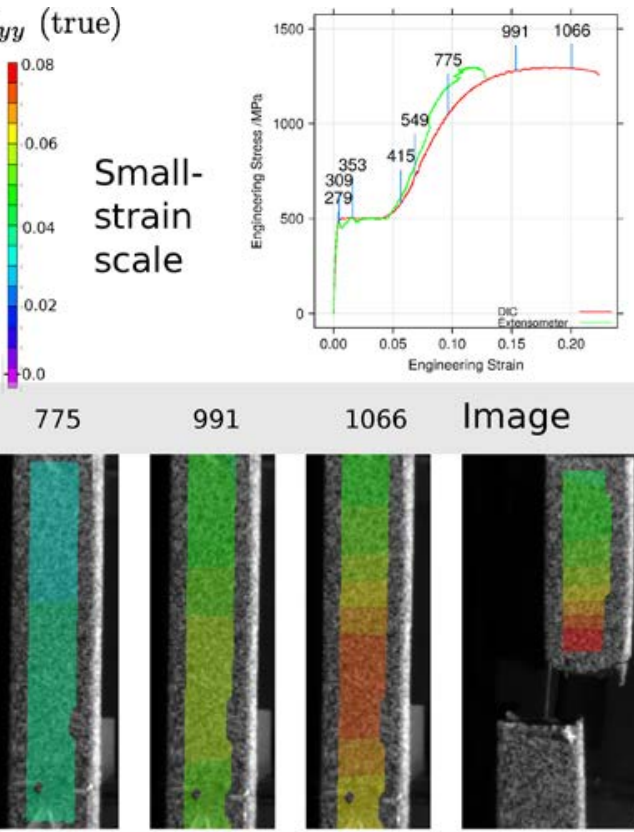

991

1066
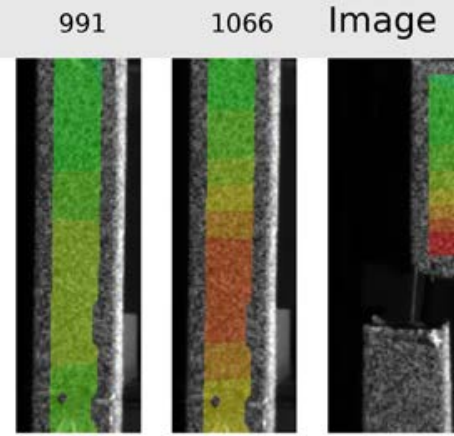

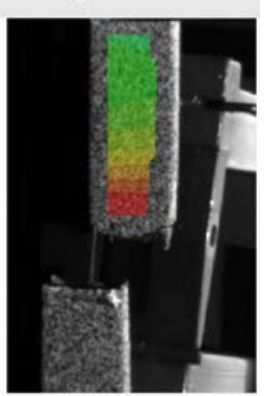

Fig. 17. Montage of specimen images overlaid with axial strain $e_{y y}$, computed from digital image correlation. The top row shows lowstrain behavior, and the bottom row shows the behavior out to failure with a larger strain scale. The plot in the upper right locates each image on the stress-strain curve.

Figure 18 shows the region of yield-point elongation in the same test, where the axial engineering strain was evaluated by both digital image correlation and read from the test-system extensometer.

The two very repeatable dips in the engineering stress measured using the extensometer, see Fig. 6, are caused by the nucleation of the two Lüders bands. The stress-strain curve developed from the DIC data contains two force drops and strain reversals that occur just after the end of the elastic region. Because the test is conducted in position control, the instantaneous elongation produced by the nucleation of a band elastically relaxes some of the force on the specimen, and therefore a portion of the elastic strain in the region where DIC strain is calculated, which produces the strain reversals.

\section{Summary}

The results of this investigation resulted in three findings enumerated in the abstract.

1. Like wrought materials, the mechanical properties of the UNS S17400 material of this study depend on the orientation introduced by the processing: Fig. 11.

2. The recommended stress-relief heat treatment increases the tensile strength, reduces the yield strength, and decreases the extent of the discontinuous yielding: Fig. 4.

3. The mechanical properties, assessed by hardness, are very uniform across the build plate, but the stress-relief heat treatment introduced a small non-uniformity that had no correlation to position on the build plate: Sec. 3.2. 


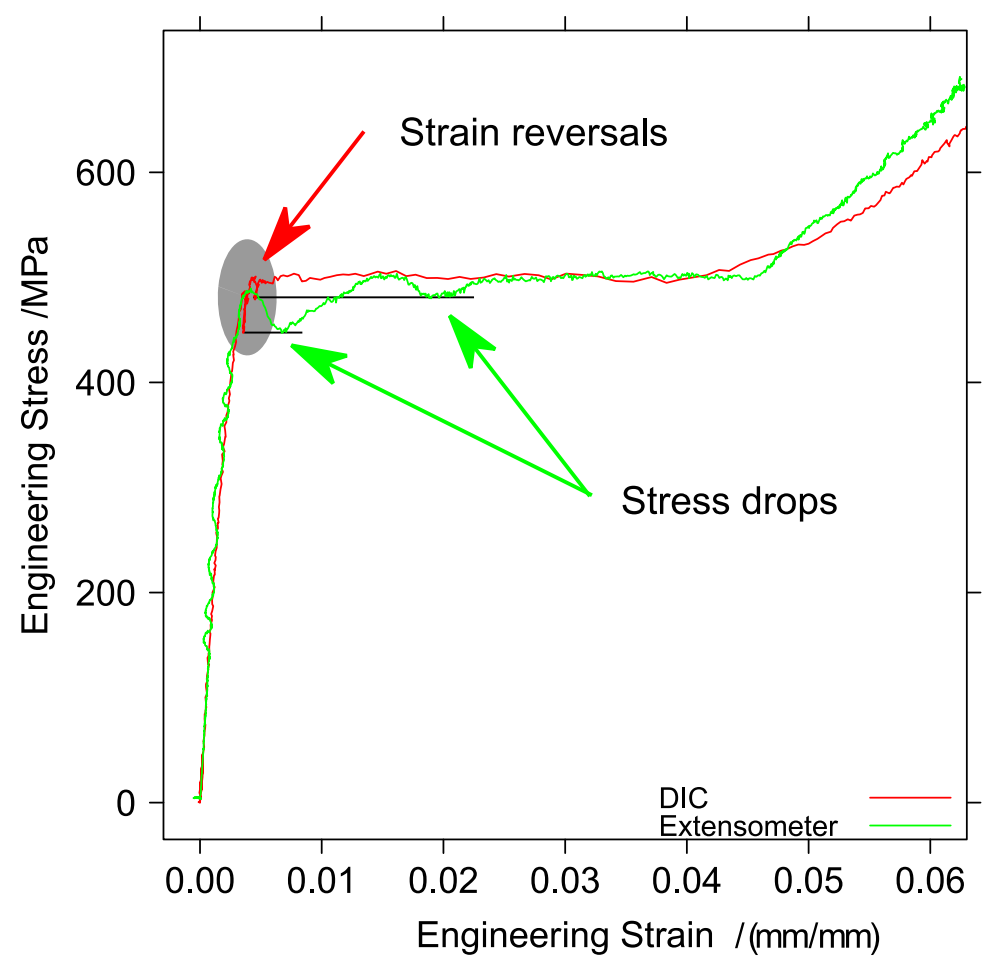

Fig. 18. Stress-strain curve during yield point elongation measured from the extensometer and from digital image correlation of the specimen gauge section.

Analysis of the mechanical property behavior resulted in four conclusions:

1. The within-build and build-to-build repeatability of the tensile properties of the UNS S17400 material steel are lower than mature engineering structural alloys, but similar to other structural alloys made by additive manufacturing, Figs. 13 and 14 and Table 4.

2. The anisotropy of the mechanical properties of the UNS S17400 material of this study is larger than that of mature structural alloys, but is similar to other structural alloys made by additive manufacturing, Figs. 15 and 16.

3. The tensile mechanical properties of the UNS S17400 material fabricated by selective laser melting are very different from those of wrought, heat-treated 17-4PH stainless steel: Fig. 12.

4. The large discontinuous yielding strain in all tests resulted from the formation and propagation of Lüders bands: Fig. 17.

Finally, these findings and conclusions lead to one recommendation:

1. It is inappropriate to refer to UNS S17400 material made by additive manufacturing as $17-4 \mathrm{PH}$ stainless steel, because it contains different phases, which led to dramatically different mechanical properties.

\section{Appendix A. Stress-Strain Curves}

Figure 19 plots all a matrix of all the stress-strain curves differentiated by build, orientation, and heat treatment. Because some builds did not produce both orientations or both heat-treated specimens, some of the entries in the matrix are blank. Some specimens produced erratic extensometer readings (build 3 no heat-treatment). The erratic measurements are caused by the extensometer slipping on the specimen. In most cases the extensometer was removed when it reached the limit of its extension and before failure. 
(a) Build 1

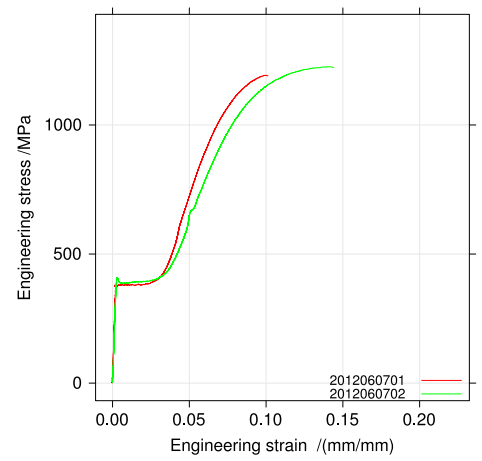

(d) Build 1; Horiz; HT:650 ${ }^{\circ} \mathrm{C} 1 \mathrm{~h}$ (b) Build 2

(e) Build 2

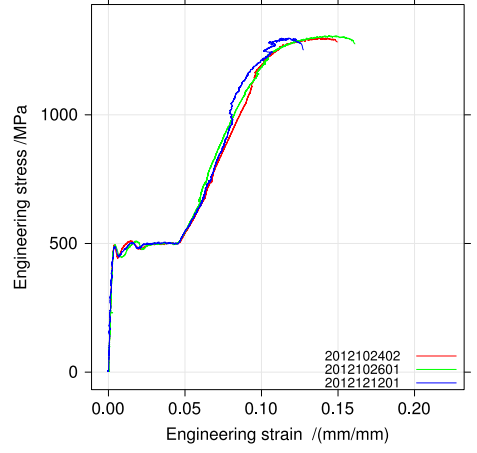

(c) Build 3; Vert; HT:650 ${ }^{\circ} \mathrm{C} 1 \mathrm{~h}$

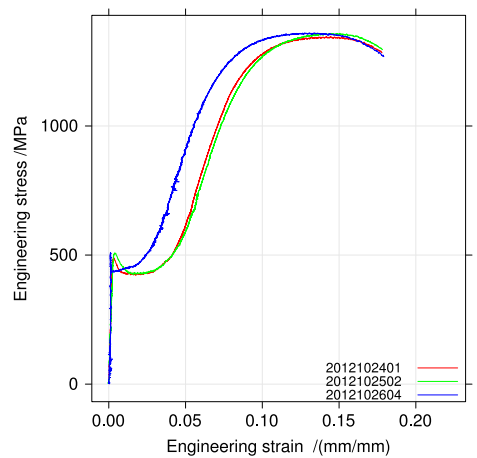

(f) Build 3; Horiz; HT:650 ${ }^{\circ} \mathrm{C} 1 \mathrm{~h}$

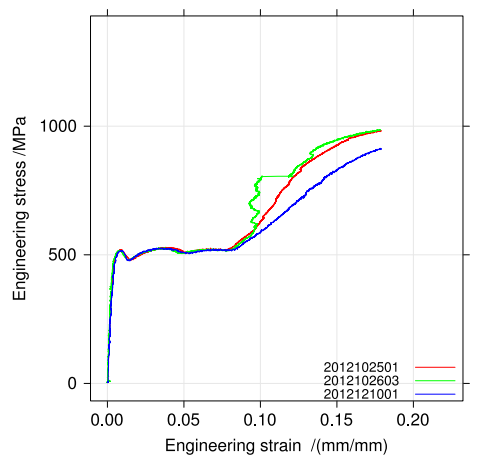

(i) Build 3; Vert; HT: none

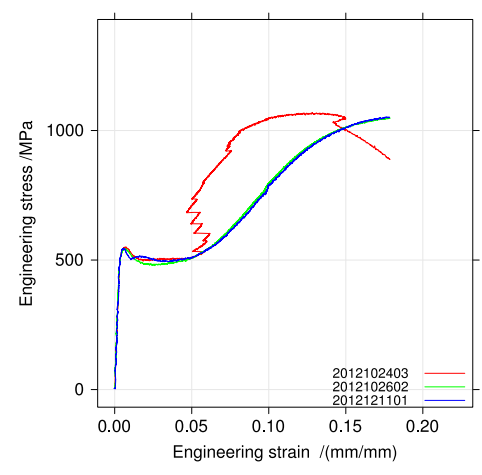

(l) Build 3; Horiz; HT: none (h) Build 2

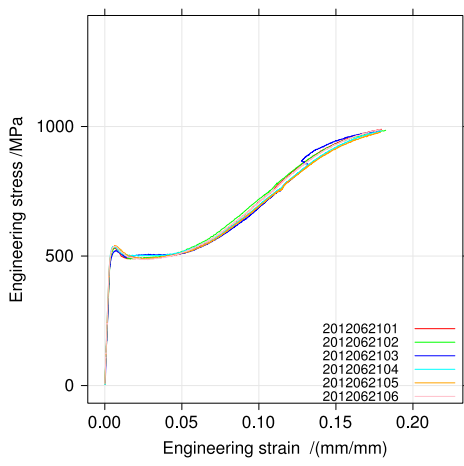

(k) Build 2; Horiz; HT: none

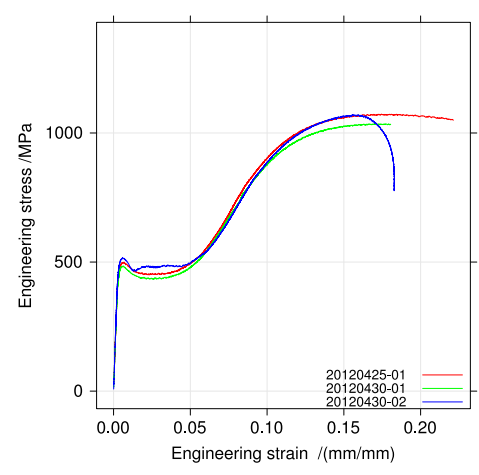

(j) Build 1; Horiz; HT: none

Fig. 19. All stress-strain curves arranged by Build and heat treatment. No data was taken in the missing entries. 


\section{Acknowledgments}

JAS fabricated the test specimens, guided the program, and wrote the introduction. WEL conducted the tensile tests, analyzed the tensile data, wrote the analysis sections. Brandon Lane, a NIST NRC Postdoctoral associate, made the hardness measurements and a preliminary analysis.

\section{References}

[1] Richard van Noort. The future of dental devices is digital. Dental Materials 28 (1), 3-12 (2012). http://dx.doi.org/10.1016/j.dental.2011.10.014

[2] BBC. Transplant jaw made by 3D printer claimed as first. http://www.bbc.co.uk/news/technology-16907104, February 2012. Accessed 2013-May 3.

[3] Oak Ridge National Laboratory. ORNL - development of a technologically significant robotic hand. http://additivemanufacturing.com/2013/01/06/ornl-development-of-revolutionary-robotic-hand/, January 2013. Accessed 2013May-3.

[4] David L. Bourell, Ming C. Leu, and David W. Rosen, editors. Roadmap for Additive Manufacturing Identifying the Future of Freeform Processing. The University of Texas at Austin Laboratory for Freeform Fabrication Advanced Manufacturing Center, 1 University Station, MC C2200, Austin TX 78712-0292 USA, 2009. Available from: http://wohlersassociates.com/roadmap2009.html.

[5] Energetics Incorporated, editor. Measurement Science Roadmap for Metal-Based Additive Manufacturing WORKSHOP SUMMARY REPORT, Columbia, Md, USA, 2013. Available from: http://events.energetics.com/NISTAdditiveMfgWorkshop/pdfs/NISTAdd_Mfg_Report_FINAL.pdf.

[6] ASTM International. Standard practice for numbering metals and alloys in the unified numbering system (UNS). Standard E527-12, ASTM International, W. Conshohocken, Pa, 2012. http://dx.doi.org/10.1520/E0527-12

[7] ASTM International. Metals and Alloys in the Unified Numbering System (UNS). Number DS-56K. ASTM International,W. Conshohocken, Pa, 12th edition, 2012. ISBN 978-0-7680-7950-0.

[8] J. A. Slotwinski, E. J. Garboczi, P. E. Stutzman, C. F. Ferraris, S. S. Watson, and M. A. Peltz. Characterization of metal powders used for additive manufacturing. J. Res. NIST 119 (2014). http://dx.doi.org/10.6028/jres.119.018

[9] ASTM International. Standard test methods for tension testing of metallic materials [metric]. Standard E8/E8M-09, ASTM International,W. Conshohocken, Pa, 2011.

[10] ASTM International. Standard practice for verification and classification of extensometer systems. Standard E83-06, ASTM International, W. Conshohocken, Pa, 2006. http://dx.doi.org/10.1520/E0083-06

[11] EOS GmbH Electro Optical Systems. Stainless Steel Training Manual. Robert-Stirling-Ring 1 D-82152 Krailling/München, April 2007. Section 16.2.

[12] US Department of Defense. Metallic materials and elements for aerospace vehicle structures. Handbook MIL-HDBK-5J, United States of America Department of Defense, Jan 2003. Available from: http://www.everyspec.com/MIL-HDBK/MIL-HDBK+(0001+-+0099)/MIL_HDBK_5J_139/.

[13] Luca Facchini, Nério Vicente, Ivan Lonardelli, Emanuele Magalini, Pierfrancesco Robotti, and Alberto Molinari. Metastable austenite in 17-4 precipitation-hardening stainless steel produced by selective laser melting. Advanced Engineering Materials 12 (3), 184-188 (2010). http://dx.doi.org/10.1002/adem.200900259

[14] Juho Talonen, Hannu Hänninen, Pertti Nenonen, and Gersom Pape. Effect of strain rate on the strain-induced -martensite transformation and mechanical properties of austenitic stainless steels. Metallurgical and Materials Transactions A 36 (2), 421432 (2005). http://dx.doi.org/10.1007/s11661-005-0313-y

[15] S. S. Hecker, M. G. Stout, K. P. Staudhammer, and J. L. Smith. Effects of Strain State and Strain Rate on Deformation-Induced Transformation in 304 Stainless Steel: 1. Magnetic Measurements and Mechanical Behavior. Metallurgical Transactions APhysical Metallurgy and Materials Science 13 (4), 619-626 (1982). http://dx.doi.org/10.1007/BF02644427

[16] EOS GmbH Electro Optical Systems. EOS stainless steel GP1 for EOSINT M 270. Technical Report MMI/04.09, EOS GmbH Electro Optical Systems, 2009. Retrieved 2013-03-29. Available from: http://www.eos.info/systems_solutions/metal/materials_material_management.

[17] Per Öfverbeck, Bo Ivarsson, Rolf Sandström, and Gustaf Östberg. Statistical evaluation of elevated temperature minimum yield/proof stress values for design purposes. International Journal of Pressure Vessels and Piping 18 (2), 135-160 (1985). http://dx.doi.org/10.1016/0308-0161(85)90048-1

[18] H. Yamanouchi, B. Kato, and H. Aoki. Statistical features of mechanical properties of current japanese steels. Materials and Structures 23 (4), 305-315 (1990). http://dx.doi.org/10.1007/BF02472204

[19] Göran A. Alpsten. Variations in mechanical and cross-sectional properties of steel. In Thomas C. Kavanagh, Fazlur Khan, Edwin H. Gaylord, and Emilio Rosenblueth, editors, Tall Building Criteria and Loading, volume 1b of Planning and Design of Tall Buildings, pages 755-805. American Society of Civil Engineers and International Association for Bridge and Structural Engineering, 1972. Proceedings-International Conference on Planning and Design of Tall Buildings, Lehigh University, Bethlehem, Pennsylvania, August 21-26, 1972.

[20] M. J. Baker. Variations in the mechanical properties of structural steels. In Proceedings of the Symposium on Concepts of Safety of Structures and Methods of Design, pages 165-174. Secretariate of the International Association for Bridge and Structural Engineering, 1969. 
[21] American Iron and Steel Institute. The variation of product analysis and tensile properties carbon steel plates and wide flange shapes. Technical report, American Iron and Steel Institute, 1000 16th St NW, Washington DC 20036, September 1974.

[22] ASTM International. Interlaboratory study to establish precision statements for astm B557, standard test methods for tension testing wrought and cast aluminum and magnesium-alloy products and B557M, standard test methods for tension testing wrought and cast aluminum- and magnesium-alloy products [metric]. Research Report E28-1004, ASTM International, 100 Barr Harbor Dr, West Conshohocken, Pa, Mar 1984. Available from: http://www.astm.org/DATABASE.CART/RESEARCH_REPORTS/RR-E28-1004.htm.

[23] Itziar Tolosa, Fermin Garcianda, Fidel Zubiri, Fidel Zapirain, and Aritz Esnaola. Study of mechanical properties of AISI 316 stainless steel processed by "selective laser melting", following different manufacturing strategies. The International Journal of Advanced Manufacturing Technology 51 (5-8), 639-647 (2010). http://dx.doi.org/10.1007/s00170-010-2631-5

[24] H. Khalid Rafi, Thomas L. Starr, and Brent E. Stucker. A comparison of the tensile, fatigue, and fracture behavior of Ti6Al4V and 15-5 PH stainless steel parts made by selective laser melting. The International Journal of Advanced Manufacturing Technology 69 (5-8), 1299-1309 (2013). http://dx.doi.org/10.1007/s00170-013-5106-7

[25] H. Meier and Ch. Haberland. Experimental studies on selective laser melting of metallic parts. Materialwissenschaft und Werkstofftechnik 39 (9), 665-670 (2008). http://dx.doi.org/10.1002/mawe.200800327

[26] L. Rickenbacher, T. Etter, S. Hövel, and K. Wegener. High temperature material properties of IN738LC processed by selective laser melting (SLM) technology. Rapid Prototyping Journal 19 (4), 282-2090 (2013). http://dx.doi.org/10.1108/13552541311323281

[27] Kai Guan, Zemin Wang, Ming Gao, Xiangyou Li, and Xiaoyan Zeng. Effects of processing parameters on tensile properties of selective laser melted 304 stainless steel. Materials and Design 50 (0), 581-586 (2013). http://dx.doi.org/10.1016/j.matdes.2013.03.056

[28] G. T. Vanrooyen. Basic Factors which Influence Lüders Strain During Discontinuous Yielding. Materials Science and Engineering 7 (1), 37-48 (1971). http://dx.doi.org/10.1016/0025-5416(71)90059-0

[29] S. Kyriakides and J. E. Miller. On the propagation of Lüders bands in steel strips. Journal of Applied Mechanics 67 (4), 645 654 (2000). http://dx.doi.org/10.1115/1.1328348

About the authors: William Luecke is a Materials Research Engineer in the Mechanical Performance Group of the Materials Science and Engineering Division of the Material Measurement Laboratory. John A. Slotwinski has a Ph.D. in physics from The Catholic University of America and most recently was a project leader for the Additive Manufacturing Materials Project in the Production Systems Group in the NIST Engineering Laboratory's Intelligent Systems Division. Currently Dr. Slotwinski is an Additive Manufacturing Development Engineer at The Johns Hopkins University Applied Physics Laboratory. He also serves on the Executive Committee of ASTM International's F42 Committee on Additive Manufacturing Technologies and is Chair of the F42.01 sub-committee on Additive Manufacturing Test Methods. The National Institute of Standards and Technology is an agency of the U.S. Department of Commerce. 